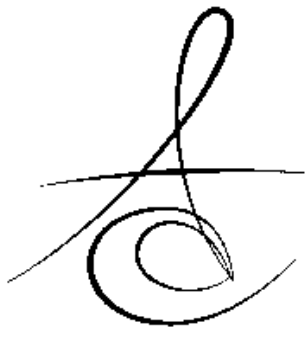

\section{GÜNÜMÜZ ADEZIVLERİNİN ÇÜRÜKSÜZ SERVİKAL LEZYON RESTORASYONLARINDAKİ ETKİNLİĞİNİN İNCELENMESİ: SİSTEMATİK DERLEME}

\section{ANALYZING CLINICAL RESEARCHES THAT EVALUATING EFFECTIVENESS OF CONTEMPORARY ADHESIVES ON NON-CARIOUS CERVICAL LESION RESTORATION: A SYSTEMATIC REVIEW}

\author{
Yrd. Doç. Dr.Neslihan TEKÇE*
}

Dr.Safa TUNCER ${ }^{* *}$

\author{
Prof. Dr.Mustafa DEMİRCí丶
}

Arş. Gör. Dt. Merve Efe SERİM *

Makale Kodu/Article code: 1961

Makale Gönderilme tarihi: 06.11.2014

Kabul Tarihi: 18.02.2015

\section{ÖZET}

$\mathrm{Bu}$ derlemenin amacı, günümüz adeziv sistemlerin çürüksüz servikal lezyonlardaki etkinliğini inceleyen klinik değerlendirme çalışmalarını derlemek ve bu çalışmalarda uygulanan araştırma metotları, hasta ve restorasyon seçim kriterleri ile klinik değerlendirme kriterlerini incelemektir.

2004-2014 yılları arasında Pubmed'de yayınlanmış olan ve çürüksüz servikal lezyonlarda adezivlerin etkinliğini inceleyen 46 araştırma incelenmiştir.

$\mathrm{Bu}$ derlemede incelenen 46 çalışmada, üç aşamalı 'etch and rinse' adeziv sistemler ile iki aşamalı 'self etch' adeziv sistemlerin kinik başarı oranlarının iki aşamalı 'etch and rinse' sistemlerden daha yüksek olduğu saptandı. Ayrıca, güncel 'all-in-one' dentin bonding ajanların, altın standart olarak kullanılan bonding ajanlar (üç aşamalı total-etch Optibond FL, iki aşamalı self-etch Clearfil SE Bond) kadar başarılı olduğu gösterilmiştir. İncelenen çalışmalarda, hasta ve restorasyon sayılarının çok farklı aralıklarda olduğu belirlenmiştir. Ayrıca çalışmalarda uygulanan araştırma yöntemlerinin her çalışmada değişkenlik gösterdiği ve bununla ilgili standart bir protokolün olmadığı gözlemlenmiştir.

Anahtar kelimeler: Adeziv sistemler, sistematik derleme, çürüksüz servikal lezyonlar.

\section{GİRİs}

Direkt yöntem ile yapılan arka bölge kompozit restorasyonlar, ağız içindeki ideal dayanıklılıklarını 5-7 yıl sürdürebilirler. ${ }^{1,2}$ Restorasyonların en büyük başarısızlık sebebi tutuculuk kaybı ve kenar uyumlarının bozulmasıdır. ${ }^{2-4} 1990$ 'I yıllarda 'etch-and-rinse'

\footnotetext{
*Kocaeli Üniversitesi Diş Hekimliği Fakültesi, Restoratif Diş Tedavisi ABD

** İstanbul Üniversitesi Diş Hekimliği Fakültesi, Diş Hastalıkları ve Tedavisi ABD
}

The purpose of this paper was to review the clinical assessment researches which reviewed by clinical effectiveness of contemporary adhesives at noncarious cervical lesions and also to analyze the clinical investigation methods, patient and restoration selection and evaluation criterias.

46 clinical researches which analyzed of effectiveness of adhesives on non-carious cervical lesions and also published on Pubmed between 2004-2014 years, were examinated.

In the 46 studies that analyzed in this review were determined three-step etch and rinse adhesives and two-step self-etch adhesives exhibited successful clinical effectiveness, whereas two-step etch and rinse adhesives displayed relatively low clinical effectiveness. Also, the contemporary all-in-one dentin bonding adhesives showed good clinical effectiveness as much as gold standard (Optibond FL and Clearfil SE Bond) dentin bonding agents. The number of restorations and patients was found very different from each other in every study. Also, the investigation methods that used in researches demonstrated variability and a standard protocol was not observed associated this.

Keywords: Adhesive systems, systematic review, non-carious cervical lesions.

tekniğinin geliştirilmesi ile adeziv restorasyonlar klinik olarak başarılı kabul edilebilecek retansiyon oranı sergilemeye başlamışlardır. Günümüzde adezivlerin geliştirilmesi ve basitleştirilmesi sonucunda, hekim dostu olarak tanımlanan dentin bağlayıcılar kliniklerde daha sıklıkla tercih edilir olmuştur. ${ }^{1,5}$ 
Mine ve dentine bağlanma mekanizması, mineral yapısının sert dokudan uzaklaşarak, onun yerine reçine monomerlerin infiltre olması ile gerçekleşir. Mineral yapısının arkasında bıraktığı poröz alanlara, reçine monomerin dolması, mikromekanik kilitlenmenin gerçekleşmesi ve arkasından polimerizasyon işleminin tamamlanması ile birlikte adezyon mekanizması gerçekleşmiş olur. ${ }^{6,7}$

'Etch-and-rinse' sistemlerde \%30-40'lık fosforik asitin uygulanması ve arkasından yıkanması ile birlikte mikropürüzlendirme gerçekleşir. Bu işlemin arkasından primerin uygulanması ve primerin açtığı yolda adezivin ilerlemesi ile birlikte geleneksel üç aşamalı uygulama işlemi gerçekleşmiş olur. ${ }^{8}$ Günümüzde 'etch-and-rinse' tekniği, hala mine dokusuna en etkin, yeterli ve dayanıklı bağlanmayı gerçekleştirmektedir. ${ }^{9}$ Dentin dokusunda ise, 'etch-and-rinse' sistemlerin temel bağlanma mekanizması difüzyon ve hibridizasyona dayanır, diğer bir deyişle rezinin kollagen fibriller arasına girerek mikro-mekanik kilitlenme sağlaması ile bağlanma gerçekleşir. Basitleştirilmiş iki aşamalı 'etchand-rinse' sistemlerde, primer ve adeziv tek bir şişede birleştirilmiş ve adezivin kaviteye tek aşamada uygulanması sağlanmıştır. ${ }^{9}$

'Self-etch' adezivlerde, dentini kendinden asitleyen ve primerleyen (non-rinse) asidik monomerlerin kullanımı ile asitleme ve primer uygulama aşamaları ortadan kaldırılmıştır. Kavitenin yıkanmasına gerek yoktur, klinik olarak adezivin uygulama süresi kısalmıştır ve en önemlisi teknik hassasiyet azalmıştır. ${ }^{8}$

'Self etch' adezivler uygulama aşamalarına göre sınıflandığı gibi, asidite düzeyine göre de sınıflandırımaktadırlar. Güçlü 'self etch' adezivlerin pH'sı 1 den küçük iken, hafif asidik 'self etch' adezivlerin pH'sı ortalama 2 civarındadır. Güçlü asidik 'self etch' adezivler 'etch-and-rinse' mekanizmasına benzer bir morfolojide bağlanma gerçekleştirirken, hafif asidik 'self-etch' adezivler dentini kısmen çözerek yüzeysel bir hibrit tabakası oluşumu sağlarlar. Bu sığ alanda gerçekleşen bağlanmaya ilaveten bu adezivler, diş yapısında kalan hidroksiapatitlerle de kimyasal bir bağlanma gerçekleştirerek, adezyonun kuvvetlenmesine sebep olurlar. ${ }^{10}$

Günümüz adezivlerinin son yıllardaki hızlı gelişimi, araştırmacıları bu konuda yoğun laboratuar çalışmaları yapmaya itmiştir. Laboratuar çalışmalarının ideal koşullarda ve çoğunlukla çürüksüz dişlerde yapıldığı ve elde edilen verilerin birçok değişkenden etkilenebileceği unutulmamalıdır. Ayrıca, laboratuar çalışmalarında, ağız içinde gerçekleşen bütün yaşlandırma faktörlerini aynı anda taklit edebilecek bir ortam henüz oluşturulamamıştır. Bu nedenle, hala klinik çalışmalar klinisyenlere adezivler ve materyaller hakkında en geçerli bilgileri sağlamaktadır. ${ }^{11}$

Peumans ve arkadaşları $^{9}$ adezivlerin başarısını inceleyecek klinik çalışmalarda çürüksüz servikal lezyonların tercih edilmesi gerektiğini bildirmiş ve bu durumu şu gerekçelerle açıklamıştır; (1) çürüksüz servikal lezyonlar makro-mekanik tutuculuk sağlamazlar; (2) çürüksüz servikal lezyonlarda bağlanma alanının en az \% 50'si dentin dokusundan oluşmaktadır; (3) hem mine hem dentin dokusunu içerirler; (4) aynı ağızda yaygın olarak bulunabilirler; (5) çoğunlukla erişimi kolay olan ön dişlerde ve premolar dişlerde bulunurlar; (6) çok az preparasyon gerektirirler ve restorasyonların yapımı nispeten kolaydır; (7) kullanılan kompozitin özellikleri sonucu etkilememektedir; (8) adezyon ya da bağlanmanın başarısızlığının göstergesi olan restorasyonların kaybı, bu tip restorasyonlarda uygulanan bağlayıcı ajanı değerlendirmenin en objektif değerlendirme parametresidir. ${ }^{12}$

\section{Çürüksüz Servikal Lezyonlarda Sınıflama}

Çürüksüz servikal lezyonlara sahip dişlerde çalışmanın bazı dezavantajları vardır. Bu lezyonlara restorasyonlar yapılırken araştırmacılar sklerotik dentin yüzeyinde işlem yapmak zorundadırlar. Kavite büyüklükleri her ağızda farklıdır ve lezyonları standardize etmek zordur. Bazı araştırmacılar ${ }^{13}$ klinik çalışmada incelenecek olan materyalin uygulandığı kaviteyi tanımlarken; 'eşit büyüklükte servikal lezyon ifadesini kullanmakla yetinirken, bazı araştırmacılar çalışmalarında kavite büyüklük ve şekilleri hakkında detaylı tanımlama yapmaktadır (Tablo 1). Peumans ve arkadaşları ${ }^{14}$ çürüksüz servikal lezyonları şekil, derinlik, serviko-insizal yükseklik, dentinin skleroze olma derecesi, atrizyon varlığı ve pre-operatif hassasiyet varlığına göre sınıflamıştır (Tablo 1). Sklerotik dentinin skleroze olma derecesi, kavite duvarı ile dişin dış yüzeyi arasındaki açısının incelenmesi ile yapılır ve Heymann ve Bayne ${ }^{15}$ sklerotik dentini bu kritere göre, Tablo $2^{\prime}$ de görüldüğü gibi 4 sınıfa $\left(45^{\circ}<\right.$; $45^{\circ}-90^{\circ} ; 90^{\circ}-135^{\circ} ;>135^{\circ}$ ) ayırmıştır. 
Tablo 1. Sınıf V lezyonların sınıflandırılması. ${ }^{9}$

\begin{tabular}{|l|l|}
\hline \multirow{3}{*}{ Şekil } & $\begin{array}{l}\text { Keskin kenarlı } \\
\text { Yuvarlak hatlı }\end{array}$ \\
\hline Derinlik & $\begin{array}{l}1 \mathrm{~mm}<\text { derinlik } \\
1 \mathrm{~mm}>\text { derinik }\end{array}$ \\
\hline \multirow{3}{*}{ Serviko-insizal yükseklik } & $<1,5 \mathrm{~mm}$ \\
\cline { 2 - 2 } & $1,5-2,5 \mathrm{~mm}$ \\
\cline { 2 - 2 } & $>2,5 \mathrm{~mm}$ \\
\hline \multirow{3}{*}{ Sklerotik dentin derecesi } & Skleroz yok \\
\cline { 2 - 2 } & Hafif sklerotik dentin (opak) \\
\cline { 2 - 2 } & Orta sklerotik dentin (sarı) \\
\cline { 2 - 2 } & Şiddetli sklerotik dentin (translusent) \\
\cline { 2 - 2 } Atrisyon faset & Yok \\
\hline \multirow{2}{*}{ Pre-operatif hassasiyet } & Var \\
\cline { 2 - 2 } & Yok \\
\hline
\end{tabular}

Tablo 2. Modifiye skleroz skalası. ${ }^{15}$

\begin{tabular}{|c|l|}
\hline Kategori & \multicolumn{1}{|c|}{ Tanımı } \\
\hline $\mathbf{1}$ & $\begin{array}{l}\text { Sklerotik alan yok, dentin beyazımsı, açık sarı renkte, } \\
\text { opak ya da hafif translusenside (bu lezyon tipi özellikle } \\
\text { genç bireylerde görülür) }\end{array}$ \\
\hline $\mathbf{2}$ & $\begin{array}{l}\text { Kategori 1'den daha fazla ancak, kategori 3 ve 4 'den } \\
\text { daha az miktarda sklerotik alan (dentin yüzeyinin \% } \\
50 \text { 'sinden daha az sklerotik alan varlığı }\end{array}$ \\
\hline $\mathbf{3}$ & $\begin{array}{l}\text { Kategori 4'den daha az miktarda sklerotik alan(dentin } \\
\text { yüzeyinin \% 50'sinden daha fazla sklerotik alan varlığı) }\end{array}$ \\
\hline $\mathbf{4}$ & $\begin{array}{l}\text { Ciddi oranda sklerotik alan varlı̆ı. Dentin koyu sarı } \\
\text { renkte ya da kahverengimsi. Dentin cam gibi } \\
\text { translusent. Bu lezyon tipi genellikle yaşı bireylerde } \\
\text { görülür. }\end{array}$ \\
\hline
\end{tabular}

\section{Klinik Çalışmalarda Çalışma Planlaması ve Hasta Seçim Kriterleri}

Klinik araştırmalar non-randomize ve randomize çalışmalar olarak iki ana gruba ayrilır. ${ }^{16}$ Kontrollü randomize klinik çalışmalar, materyallerin klinik etkinliğini inceleyen en güçlü araştırma yöntemidir. ${ }^{17}$ Restorasyonu planlanan dişlere hangi restorasyonun yapılacağına, hasta başında bir bozuk paranın yazı-tura atılması ile rastgele (randomizasyon) karar verilmektedir.

Kontrollü randomize klinik çalışmalar yapılırken restorasyonların yapılacağı lezyon içeren dişlerin seçimi ise çeşitli kriterlere göre yapılabilir;

1. Randomize- Paralel; Van Landuyt ve arkadaşları $^{18}$ randomize paralel çalışmaları her bir hasta ağzındaki lezyonların yarısına çalışmada kullanılan bir materyal, diğer yarısına başka bir materyal uygulanması şeklinde tanımlamaktadır. Paralel çalışmalarda, aynı ağızdaki azı ya da küçük azı ya da ön diş fark etmeksizin bütün çürüksüz servikal lezyonlar (non-carious cervical lesions, NCCL) çalışmaya dahil edilebilir. Lezyonun hangi çenelerde bulunduğu fark etmemektedir. Çalışmada incelenen materyal sayısından fazla sayıda restorasyon hasta ağzında mevcut ise çalışmaya dahil edilebilir. FDI World Dental Federation önerisine göre; ${ }^{19}$ randomizasyon işlemine restorasyonu planlanan en düşük numaralı dişten başlanır. İlk olarak kaviteye uygulanacak olan adeziv rastgele seçilir, alternatif/diğer adeziv ağızda bulunan diğer kaviteye (ikinci en düşük numaralı dişe) uygulanır. Bu yöntem ağızda restorasyonu planlanan başka diş de varsa bu şekilde devam eder. Eğer aynı ağızda restorasyonu planlanan dişler tek sayıda kalır ise, tek kalan dişe rastgele seçilen bir adeziv kullanılır. Yine aynı şekilde tek sayıda restorasyon sayısına sahip olan başka bir hasta olduğu durumda, ikinci adeziv ile restorasyonun yapımına devam edilir. Diğer restorasyonların yapımında randomizasyon işlemi devam eder. ${ }^{18}$

2. Pair (eşleştirme); Peumans ve arkadaşları, ${ }^{20}$ pair çalışmaları; çalışmada kullanılan 2 materyalden her birini, aynı ağızda bulunan 2 lezyona uygulanarak yapılması olarak tanımlamıştır. Üçüncü bir lezyon ağızda bulunsa bile çalışmaya dahil edilmez. Ancak pair olarak yapılan çalışmalarda hasta ağzında bulunan 2 lezyon; yan yana bulunan 1. ve 2. küçük azı dişi, ya da iki büyük azı dişi, simetrik olan iki küçük azı dişi ya da simetrik olan iki büyük azı dişi, simetrik köpek dişi ya da simetrik keser dişi olabilir.

3. Split-mouth; Gresnight ve arkadaşları ${ }^{21}$ ile Hickel ve arkadaşları, ${ }^{19}$ split-mouth tanımını birebir simetrik olan iki dişe, çalışmada kullanılan iki farklı materyalin uygulanması olarak tanımlamıştır. Hickel ve arkadaşları $^{19}$ split-mount ve pair dizayn çalışma modellerinin (tercihen splint-mount) en ideal ve klinik çalışmalarda tercih edilmesi gereken yöntemler olduğunu bildirirken; bu kriterlere uygun planlama yapılması durumunda, çalışmaya dahil edilecek olan hasta sayısının oldukça sınırlandığını da bildirmiştir. Restorasyonu planlanan dişlere hangi materyalin uygulanacağının kararı, yine rastgele yapılmaktadır.

4. Randomize- Quadrant; çalışmaya dahil olan her bir hastanın ağzında en az 4 lezyon bulunması ve bu lezyonların 4 farklı yarım çenede bulunması gerekmektedir. ${ }^{22}$ Quadrant çalışmalarda restorasyonu planlanan dişin azı ya da keser diş olması veya simetrik dişlerin olması fark etmemektedir, bu 
çalışma metodunda önemli olan 4 farklı çenedeki lezyonlara/çürüklere 4 farklı materyal/yöntemin uygulanmasıdır. Restorasyonu planlanan dişlere hangi materyalin uygulanacağının kararı, yine rastgele verilmektedir.

Bu derlemenin amacl; son 10 yılda (2004-2014 yılları arasında); günümüz adeziv sistemlerin çürüksüz servikal lezyonlardaki etkinliğini inceleyen klinik değerlendirme çalışmalarını ve bu çalışmalarda uygulanan araştırma yöntemlerini, hasta ve restorasyon seçim kriterleri ile klinik değerlendirme kriterlerini incelemektir.

\section{Gereç ve Yöntem}

$\mathrm{Bu}$ derlemede esas olarak, uygulama yöntemlerine göre sınıflandırılan dentin bağlayıcı ajanlar;

1. 3 aşamalı 'etch-and-rinse';

2. 2 aşamalı 'etch-and-rinse';

3. 2 aşamalı 'self-etch' ve

4. Tek aşamalı 'self-etch' adezivler

ve klinik çalışmalarda uygulanan araştırma yöntemleri;

1. 'Randomize paralel' grup,

2. 'Randomize pair dizayn' yöntem,

3. 'Randomize quadrant' yöntem kullanan çalışmalar incelenmiştir.

Bu derlemede, 2004-2014 yılları arasında pubmed'de yayınlanan, çürüksüz servikal lezyonlarda yapılmış olan, primer olarak adeziv sistemleri inceleyen klinik çalışmalar incelenmiştir. Bu derlemeye, çürük içeren servikal lezyonların dahil edildiği çalışmalar ile değerlendirme süresi 12 aydan kısa olan klinik çalışmalar dahil edilmemiştir. Çürüksüz servikal lezyonlar, klinik çalışmalar ve adeziv sistemler anahtar kelimeleri kullanılarak 'pub-med' taraması yapılmıştır. Çalışmaların hepsinde restorasyonlar tutuculuk (retansiyon), kenar renkleşmesi, kenar adaptasyonu, anatomik form, ikincil çürük, post-operatif hassasiyet, yüzey özellikleri ve kırılma açısından incelenmiştir. Ancak çalışmamızda, derlenen klinik araştırmalardan sadece retansiyon, kenar uyumu ve kenar renkleşmesi ile ilgili sonuçlar göz önüne alınmıştır, çünkü çürüksüz servikal lezyonlarda dentin bağlayıcıların başarısı esas olarak tutuculuklarına göre belirlenmektedir. Kenar renkleşmesi ve kenar uyumu ile ilgili problemler retansiyon kaybından önce ortaya çıkabilmekte ve retansiyon kaybının ön belirtileri olabilmektedir. İncelenen çalışmaların bir kısmında restorasyonların klinik olarak başarı düzeyi USPSH kriterlerine göre
'Alfa, Beta ve Charlie' (Tablo 3) olarak belirlendiği gibi; bir kısmında ise 0, 1, 2, 3, 4 skorlarına (Tablo 4) göre de belirlenmiştir. Buna göre değerlendirme kriterlerinden Alfa ve Beta klinik olarak kabul edilebilirliği gösterirken, Charlie restorasyonun klinik olarak kabul edilemez olduğunu göstermektedir (Tablo 3). İncelenen çalışmaların çok azında, restorasyonların klinik olarak kabul edilebilirlik düzeyi değerlendirilirken skorlama kullanılmıştır. Çalışmaların hemen hepsinde Modifiye Ryge kriterleri, yani günümüzdeki kullanılan ismi ile modifiye USPHS kriterleri (Tablo 3) kullanılmıştır. $^{23}$ Rakam ile değerlendirme yapılan çalışmalarda restorasyonlar değerlendirilirken $0,1,2$ skorları klinik olarak kabul edilebilir olarak değerlendirilirken; 3, 4 skoru klinik olarak kabul edilemez olarak kabul edilmiştir (Tablo 4). ${ }^{24}$ Bütün çalışmalarda klinik değerlendirme, birbirinden bağımsız ve çalışmadan habersiz iki deneyimli araştırmacı tarafından (çift-kör olarak) yapılmıştır. İki araştırıcı arasında değerlendirme sırasında bir anlaşmazlık durumunda, bir araya gelerek üzerinde uzlaştıkları skor kabul edilmektedir. Çalışmaların genelinde, ağız hijyeni kötü olan hastalar, kronik periodontitisi olan hastalar ile hareketli protez kullanan hastalar araştırmalara dahil edilmemiştir. İncelenen bu araştırmalarda restorasyonu planlanan her bir dişin, kontak ve karşıt dişlerinin bulunması ve oklüzyonun normal olması çalışmaya dahil edilme faktörü olmuştur. Araştırmaların hepsi sağlıklı, gönüllü ve yetişkin hastalarda, ayrıca hepsi üniversite hastanesine başvuran hastalarda yapılmıştır. Çalışmaların büyük çoğunluğunda kaviteler, restorasyon yapılmadan önce pomza ve su yardımı ile temizlenmiştir. Çalışmalarda restorasyonların yapılacağı dişlerin izolasyonu rubber dam ile ya da pamuk tampon, retraksiyon ipi ve tükürük emici ile yapılmıştır.

Çalışmamızda ele alınan bu klinik değerlendirme araştırmalarında, uygulanan dentin adezivin tipi, çalışmalarda kullanılan araştırma yöntemi, hasta sayıları, restorasyon sayıları ve klinik değerlendirme süreleri (Tablo 5 ve 6) de ayrıca değerlendirilmiştir. 
Atatürk Üniv. Diş Hek. Fak. Derg.

J Dent Fac Atatürk Uni

TEKÇE, DEMİRCI, TUNCER,

Supplement: 12, Yll: 2015, Sayfa : 104-116

SERİM

Tablo 3. Modifiye USPHS kriterleri. ${ }^{23}$

\begin{tabular}{|c|c|c|}
\hline Kategori & Kabul edilebilir & Kabul edilemez \\
\hline Retansiyon & $\begin{array}{l}\text { Alfa-Restorasyonda } \\
\text { tutuculuk kaybı yok. } \\
\text { Beta-Restorasyonda } \\
\text { kısmi kayı var, ancak } \\
\text { klinik olarak kabul } \\
\text { edilebilir düzeyde. }\end{array}$ & $\begin{array}{l}\text { Charlie-Restorasyonda } \\
\text { tamamen ya da } \\
\text { kısmen kayıp varlığı. }\end{array}$ \\
\hline $\begin{array}{l}\text { Kenar } \\
\text { renkleşmesi }\end{array}$ & $\begin{array}{l}\text { Alfa-Restorasyonun } \\
\text { kenarında renkleşme } \\
\text { yok. } \\
\text { Beta-Restorasyon } \\
\text { sinılarında kenar } \\
\text { boyunca yüzeyel } \\
\text { renkleşme var. Ancak } \\
\text { bu renkleşme cila ile } \\
\text { uzaklaştırlabiliyor. } \\
\end{array}$ & $\begin{array}{l}\text { Charlie-Restorasyon } \\
\text { sınııından pulpaya } \\
\text { doğru inen, cila ile } \\
\text { uzaklaştırılamayan } \\
\text { derin renk değişikliği } \\
\text { mevcut. }\end{array}$ \\
\hline $\begin{array}{l}\text { Kenar } \\
\text { uyumu }\end{array}$ & $\begin{array}{l}\text { Alfa-Restorasyon } \\
\text { sınılarında sondla } \\
\text { hissedilen ya da gözle } \\
\text { görülebilen bir aralanma } \\
\text { yok. } \\
\text { Beta-Restorasyon } \\
\text { kenarında mine } \\
\text { düzeyinde küçük çatlak } \\
\text { mevcudiyeti. }\end{array}$ & \begin{tabular}{ll}
\multicolumn{2}{l}{ Charlie-Restorasyon } \\
sınırında & dentin \\
dokusunu & içeren \\
açıklık varlığı. &
\end{tabular} \\
\hline
\end{tabular}

Tablo 4. Skor üzerinden klinik değerlendirme kriterleri. ${ }^{24}$

\begin{tabular}{|c|c|c|}
\hline Kategori & Kabul edilebilir & Kabul edilemez \\
\hline Retansiyon & $\begin{array}{l}\text { 0-Restorasyonun } \\
\text { yenilenmesini } \\
\text { gerektirecek belirgin bir } \\
\text { retansiyon kaybı yok. }\end{array}$ & $\begin{array}{l}\text { 1-Restorasyon } \\
\text { hareketli } \\
\text { yenilenme } \\
\text { endikasyonu var. }\end{array}$ \\
\hline $\begin{array}{l}\text { Kenar } \\
\text { renkleşmesi }\end{array}$ & $\begin{array}{l}\text { 0-Restorasyon } \\
\text { kenarlarında herhangi bir } \\
\text { renkleşme yok. } \\
\text { 1-Hafif renkleşme var } \\
\text { ancak cila } \\
\text { düzeltilebiliyor. } \\
\text { 2- Renkleşme var ve cila } \\
\text { ile düzeltilemiyor. }\end{array}$ & $\begin{array}{l}\text { 3-Restorasyon } \\
\text { kenarları bütünüyle ve } \\
\text { belirgin olarak } \\
\text { renkleşmiş durumda } \\
\text { ve cila ile ortadan } \\
\text { kaldırılamıyor. }\end{array}$ \\
\hline $\begin{array}{l}\text { Kenar } \\
\text { uyumu }\end{array}$ & $\begin{array}{l}\text { 0-Restorasyon kenarları } \\
\text { düzenli, sond takılmıyor. } \\
\text { 1-Sond takılıyor ancak } \\
\text { kavite kenarlarında gözle } \\
\text { görülür bir aralanma yok. } \\
\text { 2-Restorasyon kenarında } \\
\text { mineyi açı̆g çıkaran } \\
\text { küçük çatlak varlığı. }\end{array}$ & $\begin{array}{l}\text { 3-Restorasyon } \\
\text { kenarında belirgin } \\
\text { aralanma mevcut, } \\
\text { dentin açıkta. } \\
\text { 4-Restorasyon } \\
\text { hareketli ya da kırı. }\end{array}$ \\
\hline
\end{tabular}

Tablo 5. 2004-2014 yılları arasında çürüksüz servikal lezyonlar üzerinde yapılan klinik başarı değerlendirme çalışmalarında uygulanan araştırma yöntemleri, hasta sayıları, restorasyon sayıları, değerlendirme süreleri ve çalışmalarda kullanılan adeziv sistemler.

\begin{tabular}{|c|c|c|c|c|c|c|}
\hline Araştırmacılar & Yilı & $\begin{array}{l}\text { Çalışma } \\
\text { dizaynı }\end{array}$ & $\begin{array}{l}\text { Hasta } \\
\text { sayısı }\end{array}$ & $\begin{array}{l}\text { Restorasy } \\
\text { on sayısı }\end{array}$ & $\begin{array}{l}\text { Çalışmanın } \\
\text { süresi (ay) }\end{array}$ & Adeziv \\
\hline Matis ve ark. ${ }^{40}$ & 2004 & Pair & 30 & 80 & 36 & $\begin{array}{l}\text { FL Bond } \\
\text { Scotchbond MP }\end{array}$ \\
\hline Aw ve ark. ${ }^{30}$ & 2004 & Pair & 57 & 171 & 12 & $\begin{array}{l}\text { Scotchbond MP } \\
\text { Single Bond } \\
\text { One Coat Bond }\end{array}$ \\
\hline Van Dijken ${ }^{31}$ & 2004 & Pair & 46 & 144 & 24 & $\begin{array}{l}\text { Clearfil Liner Bond } \\
\text { One Coat Bond } \\
\text { Adper Prompt L Pop }\end{array}$ \\
\hline Bittencourt ve ark. ${ }^{32}$ & 2005 & Pair & 39 & 78 & 18 & $\begin{array}{l}\text { Single Bond } \\
\text { Adper Prompt L Pop }\end{array}$ \\
\hline Peumans ve ark. ${ }^{14}$ & 2005 & Paralel & 29 & 100 & 36 & Clearfil SE Bond \\
\hline Aw ve ark. ${ }^{33}$ & 2005 & Pair & 57 & 171 & 18 & $\begin{array}{l}\text { Scotchbond MP } \\
\text { Single Bond } \\
\text { OneCoat Bond }\end{array}$ \\
\hline Brackett ve ark. ${ }^{34}$ & 2005 & Paralel & 25 & 76 & 18 & $\begin{array}{l}\text { Tyrian } \\
\text { One-Step }\end{array}$ \\
\hline Perdigao ve ark. ${ }^{35}$ & 2005 & Paralel & 34 & 120 & 18 & Clearfil SE Bond \\
\hline Türkün ${ }^{27}$ & 2005 & Paralel & 35 & 163 & 12 & $\begin{array}{l}\text { Clearfil Protect Bond } \\
\text { Xeno III }\end{array}$ \\
\hline Meerbeek ve ark. ${ }^{36}$ & 2005 & Pair & 29 & 100 & 24 & Clearfil SE Bond \\
\hline Kubo ve ark. ${ }^{22}$ & 2006 & Quadrant & 8 & 72 & 60 & $\begin{array}{l}\text { Clearfil Liner Bond II } \\
\text { Single Bond }\end{array}$ \\
\hline Abdalla \&Garcia Godoy ${ }^{37}$ & 2006 & Paralel & 48 & 195 & 24 & $\begin{array}{l}\text { Clearfil SE Bond } \\
\text { Hybrid Bond } \\
\text { Admira Bond }\end{array}$ \\
\hline Saboia ve ark. ${ }^{38}$ & 2006 & Pair & 14 & 56 & 24 & $\begin{array}{l}\text { Prime\&Bond } \\
\text { Single Bond }\end{array}$ \\
\hline Peumans ve ark. ${ }^{20}$ & 2007 & Pair & 71 & 142 & 84 & $\begin{array}{l}\text { Permaquick } \\
\text { Optibond FL }\end{array}$ \\
\hline Burrow ve Tyas ${ }^{39}$ & 2007 & Paralel & 20 & 92 & 36 & Clearfil SE Bond \\
\hline Van Dijken ve ark. ${ }^{25}$ & 2007 & Paralel & 119 & 337 & 156 & $\begin{array}{l}\text { All Bond 2 } \\
\text { ART Bond } \\
\text { Clearfil Liner Bond } \\
\text { Denthesive } \\
\text { Denthesive } 2 \\
\text { Gluma 2000 } \\
\text { PUB3 }\end{array}$ \\
\hline Ritter ve ark. ${ }^{26}$ & 2008 & Paralel & 30 & 105 & 36 & $\begin{array}{l}\text { i Bond } \\
\text { Gluma Solid Bond }\end{array}$ \\
\hline Van Landuyt ve ark. ${ }^{18}$ & 2008 & Paralel & 52 & 276 & 12 & $\begin{array}{l}\text { G Bond } \\
\text { Optibond FL }\end{array}$ \\
\hline Van Dijken ve ark. ${ }^{41}$ & 2008 & Paralel & 88 & 270 & 156 & $\begin{array}{l}\text { ScotchBond } \\
\text { Optibond } \\
\text { Syntac }\end{array}$ \\
\hline Türkün\&Celik ${ }^{28}$ & 2008 & Paralel & 24 & 100 & 24 & Clearfil Protect Bond \\
\hline
\end{tabular}


Atatürk Üniv. Diş Hek. Fak. Derg.

TEKÇE, DEMİRCI, TUNCER,

J Dent Fac Atatürk Uni

Supplement: 12, Yוl: 2015, Sayfa : 104-116

Tablo 5'in devamı

\begin{tabular}{|c|c|c|c|c|c|c|}
\hline Burrow\&Tyas ${ }^{42}$ & 2008 & Paralel & 11 & 60 & 12 & $\begin{array}{l}\text { Clearfil S3 Bond } \\
\text { G Bond }\end{array}$ \\
\hline Reis ve Loguercio ${ }^{43}$ & 2009 & Paralel & 84 & 84 & 36 & $\begin{array}{l}\text { Adper Single Bond } \\
\text { One Step }\end{array}$ \\
\hline Ritter ve ark. ${ }^{44}$ & 2009 & Pair & 33 & 99 & 96 & $\begin{array}{l}\text { Optibond Solo } \\
\text { Prime\&Bond }\end{array}$ \\
\hline Kubo ve ark. ${ }^{45}$ & 2009 & Quadrant & 23 & 108 & 24 & $\begin{array}{l}\text { S3 Bond } \\
\text { G Bond }\end{array}$ \\
\hline Kim ve ark. ${ }^{46}$ & 2009 & Paralel & 39 & 150 & 24 & $\begin{array}{l}\text { ScotchBond Multi-Purpose } \\
\text { Adper Prompt L Pop }\end{array}$ \\
\hline Loguercia ve ark. ${ }^{47}$ & 2010 & Pair & 33 & 66 & 24 & $\begin{array}{l}\text { All Bond SE one-step } \\
\text { All Bond SE two-step }\end{array}$ \\
\hline Peumans ve ark. ${ }^{48}$ & 2010 & Paralel & 29 & 100 & 96 & Clearfil SE Bond \\
\hline Santiago ve ark. ${ }^{49}$ & 2010 & Paralel & 30 & 70 & 24 & Excite \\
\hline Brackett ve ark. ${ }^{13}$ & 2010 & Paralel & 14 & 40 & 24 & $\begin{array}{l}\text { Clearfil SE Bond } \\
\text { Clearfil S3 Bond }\end{array}$ \\
\hline Van Dijken $^{50}$ & 2010 & Paralel & 72 & 119 & 84 & $\begin{array}{l}\text { PQ1 } \\
\text { Clearfil SE Bond }\end{array}$ \\
\hline Burrow $^{51}$ & 2011 & Paralel & 13 & 41 & 36 & Go \\
\hline Van Landuyt ve ark. ${ }^{52}$ & 2011 & Paralel & 52 & 276 & 36 & $\begin{array}{l}\text { G Bond } \\
\text { Optibond FL }\end{array}$ \\
\hline Fron ve ark. ${ }^{53}$ & 2011 & Pair & 28 & 56 & 24 & Bond Force \\
\hline Burrow ve ark. ${ }^{54}$ & 2012 & Paralel & 10 & 45 & 60 & G Bond \\
\hline Van Dijken ve Pallesen ${ }^{55}$ & 2012 & Paralel & 60 & 139 & 84 & Xeno III \\
\hline Burrow and Tyas ${ }^{56}$ & 2012 & Paralel & 11 & 60 & 36 & $\begin{array}{l}\text { G Bond } \\
\text { Clearfil S3 Bond }\end{array}$ \\
\hline Perdigao ve ark. ${ }^{57}$ & 2012 & Paralel & 33 & 92 & 12 & Ambar (FGM) \\
\hline Söderholm ve ark. ${ }^{58}$ & 2013 & Pair & 21 & 84 & 48 & $\begin{array}{l}\text { i Bond } \\
\text { Clearfil SE Bond }\end{array}$ \\
\hline Dutra-correa ve ark. ${ }^{59}$ & 2013 & Paralel & 37 & 120 & 18 & $\begin{array}{l}\text { XP Bond } \\
\text { Xeno V }\end{array}$ \\
\hline Tuncer ve ark. ${ }^{29}$ & 2013 & Paralel & 24 & 123 & 24 & $\begin{array}{l}\text { Solo Bond M } \\
\text { Futurabond NR }\end{array}$ \\
\hline Moosavi ve ark. ${ }^{60}$ & 2013 & Pair & 30 & 90 & 18 & $\begin{array}{l}\text { Optibond FL } \\
\text { Optibond Solo Plus } \\
\text { Optibond AiO }\end{array}$ \\
\hline Da Costa ve ark. ${ }^{61}$ & 2013 & Pair & 42 & 84 & 12 & Excite \\
\hline Say ve ark. ${ }^{62}$ & 2014 & Paralel & 22 & 104 & 36 & AdheSE \\
\hline Zander-Grande ve ark. ${ }^{63}$ & 2014 & Paralel & 31 & 124 & 24 & $\begin{array}{l}\text { Adper Prompt L Pop } \\
\text { Xeno III }\end{array}$ \\
\hline Preussker ve ark. ${ }^{64}$ & 2014 & Paralel & 42 & 122 & 36 & Futurabond NR \\
\hline Torres ve ark. ${ }^{65}$ & 2014 & Pair & 30 & 136 & 60 & Prime\&Bond NT \\
\hline
\end{tabular}

Tablo 6. 2004-2014 yılları arasında çürüksüz servikal lezyonlarda yapılan çalışmalarda kullanılan dentin bağlayıc ajanlar ve klinik başarı oranları (\%).

\begin{tabular}{|c|c|c|c|c|}
\hline & $\begin{array}{c}\text { Kenar uyumu } \\
\text { (\%başarı oranı) }\end{array}$ & $\begin{array}{l}\text { Kenar renkleşmesi } \\
\text { (\%başarı oranı) }\end{array}$ & $\begin{array}{l}\text { Tutuculuk oranı } \\
\text { (\%başarı oranı) }\end{array}$ & $\begin{array}{c}\text { Yıllık başarısızlık } \\
\text { oranı }(\%)\end{array}$ \\
\hline \multicolumn{5}{|c|}{3 Aşamalı etch and rinse } \\
\hline Scotchbond MP & $96^{33}$ & $87^{33}$ & $88^{33}, 38^{41}, 98^{30}$ & $8^{33}, 4.7^{41}, 2^{30}$ \\
\hline Permaquick & $29^{20}$ & $76^{20}$ & $87^{20}$ & $1.8^{20}$ \\
\hline Optibond FL & $63^{52}, 26^{20}, 62^{18}$ & $87^{52}, 76^{20}, 94^{18}$ & $96^{52}, 94^{20}, 99^{18,} 97^{60}$ & $0.8^{20}, 1.3^{52}, 1^{18}, 2^{60}$ \\
\hline GLUMA Solid Bond & $92^{26}$ & $100^{26}$ & $100^{26}$ & $0^{26}$ \\
\hline Optibond & - & - & $59^{41}$ & $3.1^{41}$ \\
\hline Syntac & - & - & $64^{41}$ & $2^{41}$ \\
\hline Allbond 2 & - & - & $46^{25}$ & $4.1^{25}$ \\
\hline Clearfil Liner Bond & - & - & $74^{25}, 91^{72}$ & $2^{25}, 4.5^{31}$ \\
\hline Denthesive & - & - & $5^{25}$ & $7.3^{25}$ \\
\hline \multicolumn{5}{|c|}{2 Aşamalı etch and rinse } \\
\hline Single Bond & $97^{22}, 100^{43}, 100^{32}$ & $100^{22}, 100^{43}, 100^{38}, 100^{32}$ & $\begin{array}{l}100^{22}, 81^{33,} 92^{43}, 90^{38} \\
100^{32}, 91^{30}\end{array}$ & $\begin{array}{l}0^{22}, 12.6^{33}, 2.6^{43}, 5^{38}, \\
0^{32}, 9^{30}\end{array}$ \\
\hline One Coat Boat & $88^{33}$ & $86^{33}$ & $90^{33}, 93^{30}, 87^{31}$ & $6.6^{33}, 7^{30}, 6.5^{31}$ \\
\hline One Step & $100^{34}, 100^{43}$ & $100^{34}, 100^{43}$ & $100^{34}, 51^{43}$ & $16.3^{43}$ \\
\hline Optibond Solo & $60^{44}$ & $45^{44}$ & $69^{44}$ & $3.8^{44}$ \\
\hline Solobond M & $100^{29}$ & $100^{29}$ & $88^{29}$ & $6^{29}$ \\
\hline
\end{tabular}


Tablo 6'nın devamı

\begin{tabular}{|c|c|c|c|c|}
\hline XP Bond & $88^{59}$ & $100^{59}$ & $100^{59}$ & $0^{59}$ \\
\hline Optibond Solo Plus & - & - & $93^{60}$ & $4.6^{60}$ \\
\hline Prime\&Bond NT & $72^{65}$ & $69^{44}, 75^{65}$ & $59^{44}, 68^{65}$ & $5.1^{44}, 6.4^{65}$ \\
\hline PQ1 & $60^{50}$ & $100^{50}$ & $100^{50}$ & $0^{50}$ \\
\hline Ambar (FGM) & - & - & $100^{57}$ & $0^{57}$ \\
\hline ExciTE & $96^{61}, 100^{49}$ & $96^{61}, 100^{49}$ & $88^{61}, 79^{49}$ & $12^{61}, 10.5^{49}$ \\
\hline Gluma 2000 & - & - & $16^{25}$ & $3.6^{25}$ \\
\hline Admira Bond & $100^{37}$ & $100^{37}$ & $100^{37}$ & $0^{37}$ \\
\hline \multicolumn{5}{|l|}{2 Aşamalı self-etch } \\
\hline Tyrian & $100^{34}$ & $100^{34}$ & $100^{34}$ & $0^{34}$ \\
\hline Clearfil Liner Bond II & $100^{22}$ & $100^{22}$ & $100^{22}$ & $0^{22}$ \\
\hline Clearfil SE Bond & $\begin{array}{l}100^{13}, 8^{48}, 64^{14}, 76^{50}, \\
100^{37}, 88^{36}\end{array}$ & $\begin{array}{l}100^{13}, 56^{48}, 87^{14}, 100^{50}, \\
100^{37}, 100^{36}\end{array}$ & $\begin{array}{l}84^{13}, 97^{48}, 100^{14}, 100^{50} \\
90^{39^{\prime}}, 100^{37}, 100^{35}, 100^{36}\end{array}$ & $\begin{array}{l}8^{13}, 0.3^{48}, 0^{14}, 0^{50} \\
3.3^{39}, 0^{37}, 0^{35}, 0^{36}\end{array}$ \\
\hline All Bond SE & $100^{47}$ & $100^{47}$ & $91^{47}$ & $4.5^{47}$ \\
\hline Clearfil Protect Bond & - & - & $100^{28}, 100^{27}$ & $0^{28}, 0^{27}$ \\
\hline ART Bond & - & - & $59^{25}$ & $3.1^{25}$ \\
\hline Denthesive 2 & - & - & $26^{25}$ & $5.6^{25}$ \\
\hline PUB 3 & - & - & $42^{25}$ & $4.4^{25}$ \\
\hline \multicolumn{5}{|l|}{ Tek Aşamalı self-etch } \\
\hline iBond & $81^{26}$ & $69^{26}$ & $100^{26}$ & $0^{26}$ \\
\hline G-Bond & $23^{52}, 43^{18}, 100^{45}, 100^{66}$ & $\begin{array}{l}65^{52}, 87^{18}, 100^{45}, 97^{56} \\
100^{66}\end{array}$ & $\begin{array}{l}94^{52}, 99^{18}, 98^{45}, 97^{54} \\
100^{56}, 100^{66}\end{array}$ & $\begin{array}{l}2^{52}, 1^{18}, 1^{45}, 0.6^{54}, 0^{56} \\
0^{66}\end{array}$ \\
\hline Clearfil S3 Bond & $100^{13,} 100^{45}$ & $100^{13}, 100^{45}, 97^{56}$ & $81^{13}, 98^{45}, 98^{56}$ & $4.5^{13}, 1^{45}, 0.6^{56}$ \\
\hline Go & - & - & $85^{59}$ & $10^{59}$ \\
\hline AdheSE & $100^{62}$ & $100^{62}$ & $92^{62}$ & $2.6^{62}$ \\
\hline Optibond $\mathrm{AiO}$ & - & - & $90^{60}$ & $6.6^{60}$ \\
\hline Xeno V & $87^{59}$ & $87^{59}$ & $91^{59}$ & $6^{59}$ \\
\hline Futurabond NR & $100^{29}$ & $100^{29}$ & $73^{29}, 71^{64}$ & $13.5^{29}, 9.6^{64}$ \\
\hline Xeno III & $79^{55}, 100^{63}$ & $100^{55}, 100^{63}$ & $77^{55}, 97^{63}, 96^{27}$ & $3.2^{55}, 1.5^{63}, 4^{27}$ \\
\hline Adper Prompt L Pop & $100^{63}, 100^{66}$ & $100^{63}, 100^{66}$ & $97^{63}, 100^{66}, 79^{31}$ & $1.5^{63}, 0^{66}, 10.5^{31}$ \\
\hline AQ Bond Plus & $100^{66}$ & $100^{66}$ & $100^{66}$ & $0^{66}$ \\
\hline Fluoro Bond Shake-One & $100^{66}$ & $100^{66}$ & $100^{66}$ & $0^{66}$ \\
\hline Adper Prompt & $100^{32}$ & $100^{32}$ & $93^{32}$ & $4.6^{32}$ \\
\hline Prime \& Bond 2.1 & - & $91^{38}$ & $82^{38}$ & $9^{38}$ \\
\hline Hybrid Bond & $97^{37}$ & $92^{37}$ & $100^{37}$ & $0^{37}$ \\
\hline
\end{tabular}

\section{SONUÇLAR}

Bu derlemede, son 10 yılda çürüksüz servikal lezyonlara restorasyon yapılan 46 klinik çalışmada kullanılan toplam 46 adeziv sistem incelenmiştir (Tablo 5 ve 6). İncelenen çalışmaların 29 tanesi kontrollü paralel-randomize iken, 15 tanesi pair ve 2 tanesi de quadrant çalışmalardır. Çalışmalarda kullanılan adeziv sistemler ve uygulanan araştırma yöntemleri, hasta sayıları, restorasyon sayıları ve değerlendirme süreleri Tablo 5'de açıklanmaktadır. İncelenen klinik araştırmalarda, çalışmaya dahil edilen en düşük hasta sayıları 8,11 ve 14 iken, en yüksek hasta sayısı 119 'dur. Çalışmalara dahil edilen restorasyon sayısına bakıldığında, toplamda en düşük restorasyon sayısı 40 iken,

en yüksek restorasyon sayısı 337'dir. Çalışmaların genelinde kontrol grubu olarak, Clearfil SE Bond veya Optibond FL kullanılmış olup, bu sebeple de çalışmalarda en fazla incelenen iki adet bağlayıcı sistem olmuşlardır. Bu iki sisteme ilaveten çalışmalarda en sık kullanılan diğer bir bağlayıcı adeziv ajanın da G Bond olduğu belirlenmiştir. Çalışmaların süresi 12 ay ile 156 ay arasında değişmektedir. İncelenen dahil edilen hastaların yaş aralıkları belirtilmiş olup, en düşük yaşın 18 olduğu gözlemlenirken, en yüksek hasta yaşının 84 olduğu belirlenmiştir. Çalışmalarda restorasyonların klinik olarak kabul edilebilir (kenar renkleşmesi, kenar bütünlüğü, retansiyon açısından) başarı oranları Tablo 6 'da verilmiştir. Bütün çalışmalar içinde en düşük klinik performansı 13 yıl sonunda $\% 5$ başarı oranı ile Denthesive dentin bağlayıcı ajan ${ }^{25}$ ile, 13 yıl sonunda $\% 16$ klinik başarı oranı ile Admira bond sergilemiştir. ${ }^{25}$ Peumans ve ark. ${ }^{14}$ Clearfil SE Bond (Kuraray, Japonya), Kubo ve ark. ${ }^{22}$ Single Bond (3M, ESPE) ve Clearfil Liner Bond II (Kuraray, Japonya), Ritter ve ark. ${ }^{26}$ i Bond (Hereaus-Kulzer, Almanya) ve Gluma Solid Bond (Hereaus-Kulzer, Almanya), Türkün $^{27}$ ve Türkün\&Çelik ${ }^{28}$ Clearfil Protect Bond dentin bağlayııı ajanlar için klinik başarı kriteri olarak kabul edilen retansiyon oranını $\% 100$ olarak tespit etmişlerdir.

Adeziv sistemlerin yıllık başarı ve başarısızlık oranları Tablo 6'da verilmiştir. Buna göre yıllık hesaplamalar bazında en yüksek başarısızlık oranını \%13.5 olarak Futurabond $\mathrm{NR}^{29}$ sergilemiştir. En yüksek 
yıllık başarı oranını ise Clearfil SE Bond, Clearfil Protect Bond ve $\mathrm{G}$ Bond göstermiştir. Ayrıca tek bir çalışmada en fazla $7,{ }^{40}$ başka bir çalışmada ise en fazla 5 adet ${ }^{66}$ dentin bağlayıcı sistem incelenmiştir.

$\mathrm{Bu}$ derlemede incelenen klinik çalışmaların çoğunda aynı hasta ağzında, çalışmalarda kullanılan her bir materyal için birden fazla sayıda restorasyonun yapııdığı görülmüştür. Swift ve arkadaşları, ${ }^{12}$ hasta ile ilgili etkenlerin klinik çalışmaların sonuçlarını etkilemesini en aza indirmek için, çalışmada kullanılacak olan her bir materyalin aynı hasta ağzında yer alması gerektiğini bildirmiş; diğer bir deyişle, çalışmada yer alan her hastanın, çalışmada kullanılan her bir materyali ağzında taşıması gerektiğini belirtmiştir. Ayrıca araştırmacılar bir hastada, aynı adeziv sistemin 3 dişten daha fazla sayıda kullanılmaması gerektiğini de bildirmişlerdir. Hickel ve arkadaşları ${ }^{19}$ da çalışmada yer alacak olan her bir hastaya, çalışmada kullanılan bir materyalin uygulanması gerektiğini bildirmiştir. İdeal olan, bir çalışmada; bir test grubu, bir kontrol grubunun bulunmasıdır. Tek bir çalışmada birden çok değişkenin incelenmesi genellikle önerilmemektedir. Test edilen iki materyalin de aynı ağızda, aynı tip dişte ve aynı büyüklükteki kavitelerde, tercihen birebir simetrik dişte olması, bir klinik çalışma için en ideal durumdur. ${ }^{19}$ Ancak, bu şekildeki restorasyonların aynı ağızda aranması, uygun hasta sayısını oldukça sınırlar. Tek bir hastada çok sayıda restorasyon yapılması, hastaya bağı faktörlerin istatistiksel analizde etkili olmasına sebep olur. Bu durum, çalışmanın sonuçlarını etkileyeceğinden önerilmemektedir. Bu nedenle, klinik çalışmalarda 'splint-mount' ya da 'pair-tooth' çalışmalar tercih edilen test yöntemleri olmalıdır. İdeal olan, çalışmalarda yer alan her bir materyalin aynı hasta ağzında sadece bir dişe uygulanması, aynı materyalle yapılan daha fazla sayıda restorasyon aynı ağızda bulunsa dahi çalışmaya dahil edilmemesidir. Materyal sayısı kadar restorasyonun yapılması durumunda, yeterli hasta sayısına ulaşabilmek için daha fazla sayıda hastanın çalışmaya alınması gerekli olacaktır. ${ }^{19}$

Van Landuyt ve arkadaşlar ${ }^{17}$ bir çalışmanın kalitesinin, o çalışmanın istatistiksel gücü ile değerlendirildiğini bildirmişlerdir. İstatistiksel analizden başka, örnek sayısı da çalışmanın kalitesini belirlemede anahtar rol oynar. Araştırmacılar, çalışmalarııı az sayıda restorasyon ya da az sayıda hasta ile tamamlarlarsa, yapılan çalışmanın istatistiksel gücü düşük olacaktır. Hasta başına, bir ağızda, çalışmadaki her bir grup için birden fazla sayıda restorasyon yapılması durumunda, diğer bir deyişle; hasta sayısı artmadan, sadece restorasyon sayısının artması durumunda çalışmanın kalitesi olumsuz etkilenecektir. Çalışmada yapılan restorasyon sayısının yeterli, ancak hasta sayısının düşük olduğu durumlarda, uygun istatistiksel analiz elde edebilmek için hasta sayısının arttırıması gerekir. Ancak bu sefer de istatistiksel analiz, hastarestorasyon sayısı arasındaki farklılıklardan dolayı daha karmaşık bir hal alır. Van Landuyt ve arkadaşlarına ${ }^{17}$ göre, az sayıda hastada çok sayıda restorasyon yapımı yaklaşımı ile klinik çalışma yapmak, klinik çalışmanın kalitesinin azalmasına sebep olur. Bu derlemede incelenen çalışmalarda hasta ve materyal sayısı her çalışmada oldukça farklılık göstermiştir. Örneğin, Burrow ve arkadaşları ${ }^{54} 10$ hasta ile klinik çalışmaIarını tamamlamıştır. Kubo ve arkadaşları ${ }^{22}$ ise 8 hasta ile klinik çalışmalarını tamamlarken; Reis ve Loguercio 4384 hasta ile çalışmalarını tamamlamıştır. Bu iki çalışmadaki restorasyon sayısı sırasıyla 72 ve 84 'dür. Her iki çalışmadaki hasta sayısı arasında büyük farklııık varken, çalışmalarda yapılan restorasyon sayıları birbirine çok yakındır. Bu tür çalışmalarda hasta sayısının az, restorasyon sayısının fazla olmasında, çürüksüz servikal lezyonların aynı ağızda çok yaygın olarak bulunmasının etkisi olabilir.. Brackett ve arkadaşları ${ }^{13} 14$ hastada 40 restorasyon değerlendirerek dentin bağlayıcılar hakkında bilgi verirken, Van Landuyt ve arkadaşları ${ }^{52} 52$ hastada 276 restorasyonu inceleyerek dentin bağlayıcıların etkinliklerini değerlendirmiştir. Van Dijken ve arkadaşları ${ }^{25} 119$ hastada 337 restorasyon incelemişlerdir. Her bir çalış̧madaki hasta-restorasyon sayıları arasındaki uyumsuzluk çalışmaların sonuçları üzerinde etkili olmuş olabilir.

Kenar renkleşmesi, genellikle restorasyonların kenarlarındaki düzensizlikten, boşluklardan (gap), kııklardan dolayı oluşur. Kompozitin fiziksel özelliklerinin yanında, hasta ile ilgili faktörler de renkleşme üzerinde etkili olur. Hayashi ve arkadaşla$\mathrm{rI}^{30}$ yaptıkları çalışmada restorasyonları yapılan dişlerden replikalar çıkartarak restorasyonların kenar uyumunu inceledikleri çalışmada, kenar düzensizliği olan bölgelerde kenar renkleşmesinin de geliştiğini bildirmişlerdir. Mjör ve arkadaşları ${ }^{68}$ kenar renkleşmesinin ikincil çürüğün bir belirtisi olmadığını belirtirken, Hayashi ve arkadaşları ${ }^{69}$ kenar renkleşmesinin gelecekte restorasyonda oluşabilecek başarısızlıkların habercisi olabileceğini ileri sürmüşlerdir. Bu derlemede incelenen 
çalışmalara bakıldığında, birçok çalışmanın kenar uyumu başarı oranı ile kenar renkleşmesi başarı oranı (\%) birbirine çok yakındır, ya da hemen hemen aynıdır. 26-29,33,34,43,45,47,62 Ancak Peumans ve arkadaşları, ${ }^{20}$ dentin bağlayıcı ajanların etkinliklerini çürüksüz servikal lezyonlarda inceledikleri 7 yıllık klinik çalışmada, üç aşamalı Permaquick dentin bonding ajanın kenar uyumu başarı oranını \% 29 verirken, kenar renkleşmesi başarı oranını \% 76 olarak vermiştir. Yine aynı araştırmacılar, Optibond FL 'nin kenar uyumu başarı oranını \%26 verirken, kenar renkleşmesi başarı oranını \%82 olarak vermiştir. ${ }^{20}$ Peumans ve arkadaş$\mid a r{ }^{48}$ yaptıkları bir başka çalışmada, Clearfil SE Bond'un kenar uyumu başarı oranını \%8 verirken, kenar renkleşmesi başarı oranını \% 56 olarak vermiştir. Bu derlemede de incelenen çalışmalardaki restorasyonlarda, kenar uyum oranları ile kenar renkleşmesi oranları arasında doğru ya da ters bir orantı kurulamamıştır. Ayrıca, kenar renkleşmesi ile restorasyonun klinik başarısı arasında kesin ilişki kurulamayacağını doğrular şekilde, Ritter ve arkadaşları ${ }^{44}$ Optibond Solo Plus dentin bağlayıcı ajanın 96 ay sonunda, restorasyonlarda yüksek oranda kenar renkleşmesine (\%55) neden olduğu halde, kabul edilebilir klinik başarı oranı (\%69 retansiyon oranı) gösterdiklerini ifade etmiştir. ${ }^{44}$ Heintze ve arkadaşları $^{70}$ restorasyonlarda kenar renkleşmesi oluşma sıklığının, çürük gelişme sıklığından ortalama 6 kat fazla olduğunu bildirmiştir. Araştırmacılar restorasyonlardaki kenar renkleşmesi ile çürük oluşumu arasında net bir ilişki olmadığını, ayrıca kenar bütünlüğünün klinik olarak kesin kabul edilebilirlik sınırının çok belirgin olmadığını ileri sürmüşlerdir.

Brunthaler ve arkadaşları, ${ }^{71}$ klinik çalışmaları inceleyerek yaptıkları derlemede, restorasyonlarda kenar renkleşmesi oluşma sıklığının ortalama \%5,5 olduğunu ileri sürmüştür. Araştırmacılar, bu ortalamanın materyalden materyale farklılık gösterebileceğini, uygulayıcı ve hasta ile ilgili faktörlerin sonuçlar üzerinde etkisinin olabileceğini bildirmiştir. Opdam ve arkadaşları $^{72}$ ise restorasyonlarda ikincil çürük gelişme sıklığını yıllık \%5-6 olarak vermişlerdir. Kenar renkleşmesinin süreyle doğru orantılı olarak arttığı iddiası ile paralel şekilde, bu derlemede incelen çalışmalarda Brackett ve arkadaşlar ${ }^{13}$ Clearfil SE Bondun kenar renkleşmesi başarı oranını 24 ay sonunda \%100, Peumans ve arkadaşları $^{14} 36$ ay sonunda \%64, Peumans ve arkadaşları ${ }^{48} 96$ ay sonunda $\% 8$ olarak belirlemiştir. Kullanılan dentin bağlayıcıların klinik başarılarının her çalışmada farklı oranlarda çıkmasında, çalışmaların yapıldığı zaman aralığının etkisinin olabileceği gibi, uygulayıcı farklılıkları ve uygulanan araştırma yöntemlerindeki farklılıkların da etkisi olabilir.

Van Meerbeek ve arkadaşları, ${ }^{7}$ in vitro ${ }^{73}$ ve in vivo çalışmalarda ${ }^{74,75}$ üstün performans sergileyen üç aşamalı 'etch and rinse' sistem Optibond FL ile iki aşamalı 'self-etch' Clearfil SE Bond'un altın standart ${ }^{76}$ kabul edildiğini ve çalışmalarda kontrol grubu olarak kullanıldığını bildirmiştir. Araştırmacılar ayrıca, iki aşamalı 'self-etch' sistemlerin iki aşamalı 'etch and rinse' sistemlerden daha başarılı olduğunu ifade etmiştir. ${ }^{11} \mathrm{Bu}$ derlemede incelenen çalışmaların klinik olarak tutuculuk oranları incelendiğinde, dentin bağlayıcılar içinde en düşük tutuculuk oranının $\% 5^{25}$ ile üç aşamalı 'etch and rinse' sistem olan Denthesive dentin bağlayıc ajana ait olduğu belirlenmiştir. Bunun yanında, üç aşamalı 'etch-and-rinse' bağlayıcı ajanlar ile 'all-in-one' sistemleri karşılaştıran çalışmalar incelendiğinde, 'all-in-one' sistemlerin kabul edilir klinik sonuçlar sergilediği bildirilmiştir. ${ }^{13,26,54}$ Brackett ve arkadaşları $^{13} 24$ ay sonunda iki aşamalı 'self-etch' Clearfil SE Bond ve tek aşamalı 'self etch' Clearfil S3 Bond'un retansiyon oranını sırasıyla \%84 ve \%81 olarak verirken, Van Landuyt ve arkadaşları ${ }^{52} 36$ ay sonunda Optibond FL ve G Bond'un retansiyon oranını $\% 96$ ve \%94 olarak vermiştir. Yine Van Landuyt ve arkadaşları $^{52}$ orta-uzun vadede 'all-in-one' sistemlerin altın standart olan üç aşamalı sistemler kadar başarılı klinik performans sergilediğini bildirmiştir. Benzer şekilde Brackett ve arkadaşları ${ }^{13}$ 'all-in-one' sistemler ile altın standart iki aşamalı 'self-etch' sistemlerin, Sınıf V kavitelerdeki etkinliği arasında fark bulunmadığını bildirmiştir. Kubo ve arkadaşları ${ }^{45}$ tek aşamalı adezivlerin (Clearfil S3 Bond, G Bond) 24 ay sonundaki retansiyon oranını \%98 olarak belirtmiştir. Van Landuyt ve arkadaşları ${ }^{18}$ ise çalışmada kullanılan altın standart üç aşamalı Optibond FL ve tek aşamalı G Bond'un 12 ay sonundaki retansiyon oranını \%99 olarak vermiştir.

Ayrıca yapılan klinik çalışmalarda adeziv sistemlerin incelenme süreleri arasında da farklıklar mevcuttur. Süreye bakılmaksızın, bir adeziv sistemi başarılı ya da başarısız olarak nitelendirmek yanlış olabilir. Bu derlemede incelenen 46 klinik çalışmanın 8 tanesinde 12 ay, 6 tanesinde 18 ay, 12 tanesinde ise 24 ayda, bir adeziv sistemin başarılı ya da başarısız olduğu kanaatine varılmıştır. Ancak Van Dijken ve 
arkadaşları $^{25,41}$ yaptıkları klinik çalışmalarda adezivlerin başarısını 156 ay sonunda değerlendirmişlerdir. Yapılan bu çalışmalarda adeziv sistemlerin yıllık başarı oranlarına bakılarak, bu adeziv sistemler ile ilgili başarılı ya da başarısız olarak hüküm vermek daha doğru olabilir. Bu nedenle çalışma bazında değil de, her bir çalışmadaki yıllık başarısızlık oranları da hesaplanarak Tablo 6'da verilmiştir. Böylece yıllık ortalamalar bazında en yüksek başarısızık oranını $\% 16,3$ olarak One Step ve başka bir çalışmada $\% 12^{61}$ ve $\% 10.5^{49}$ olarak Excite ve $\% 13.5$ olarak Futurabond $N^{29}$ sergilemiştir. En düşük yıllık başarısızlık oranını ya da en yüksek yıllık başarı oranlarını ise Clearfil SE Bond, Clearfil Protect Bond, G Bond adeziv sistemler sergilemiştir.

\section{KAYNAKLAR}

1. Van Meerbeek B, Perdiagao J, Lambrechts $P$, Vanherle G. The clinical performance of adhesives. J Dent 1998;26:1-20.

2. Manhart J, Chen HY, Hamm G, Hickel R. Buonocore memorial lecture, Review of the clinical survival of direct ond indirect restorations in posterior teeth of the permanent dentition. Oper Dent 2004;29:481-508.

3. Mjör IA, Gordan VV. Failure, repair, refurbishing and longevity of restorations. Oper Dent 2002;27:528-34.

4. Mjör IA, Shen C, Eliasson ST, Richter S. Placement and replacement of restorations in general dental practice in Iceland. Oper Dent 2002;27:117-23.

5. Mandras RS, Thurmond JW, Latta MA, Matranga LF, Kildee JM, Barkmeier WW. Three year clinical evaluation of the Clearfil Liner Bond System. Oper Dent 1997;22:266-70.

6. Van Meerbeek B, Van Landuyt K, De Munck J, Hashimoto M, Peumans M, Lambrechts P, Yoshida $\mathrm{Y}$, Inoue $\mathrm{S}$, Suzuki K. Technique-sensitivity of contemporary adhesives. Dent Mater J 2005;24:113.

7. Van Meerbeek B, De Munck J, Yoshida Y, Inoue S, Vargas M, Vijay P. Buonocore memorial lecture. Adhesion to enamel and dentin: current status and future challenges. Oper Dent 2003;28:215-35.

8. Munck JD, Landuyt KV, Peumans M, Poitevin A, Lambrechts P, Braem M, Meerbeek BV. A critical review of durability of adhesion to tooth tissue: Methods and results. J Dent Res 2005;84:118-32.
9. Peumans M, Kanumilli P, De Munck J, Van Landuyt K, Lambrechts P, Van Meerbeek B. Clinical effectiveness of contemporary adhesives: a systematic review of current clinical trials. Dent Mater 2005;21:864-81.

10. Yoshida Y, Nagakane K, Fukuda R, Nakayami Y, Okazaki M,Shintani $H$, Inoue S, Tagawa $Y$, Suziki K, De Munck J, Van Meerbeek B. Comparative study on adhesive performance of functional monomers. J Dent Res 2004:83:454-8.

11. Van Meerbeek B, Peumans M, Poitevin A, Mine A, Ende AV, Neves A, Munck JD. Relationship between bond strength tests and clinical outcomes. Dent Mater 2010;26:100-21.

12. Swift EJ Jr, Perdigao J, Heymann HO, Wilder AD Jr, Bayne SC, May KN Jr, Sturdevant JR, Roberson TM. Eighteen-month clinical evaluation of a filled and unfilled dentin adhesive. J Dent 2001;29:1-6.

13. Brackett MG, Dib A, Franco G, Estrada $\mathrm{BE}$, Brackett WW. Two-year clinical performance of Clearfil SE and Clearfil S3 in restoration of unabraded non-carious class $\mathrm{V}$ lesions. Oper Dent 2010;35:273-8.

14. Peumans M, Munck J, Van Landuyt K, Lambrechts $P$, Van Meerbeek B. Three-year clinical effectiveness of a two-step self-etch adhesive in cervical lesions. Eur J Oral Sci 2005;113:512-8.

15. Heymann HO, Bayne SC. Current concepts in dentin bonding: Focusing on dentinal adhesion factors. J Am Dent Assoc 1993;124:26-36.

16. Reeves BC, Deeks JJ, Higgins JPT, Wells GA. Including non-randomized studies. In: Higgins JPT, Green S, editors. Cochrane Handbook for Systematic Reviews of Interventions Version 5.1.0 (updated March 2011). The Cochrane Collaboration. 2011.

17. Van Landuyt K, Fieuws S, Meerbeek BR. Sample size considerations for restoration-longevity randomized controlled trials. J Adhes Dent 2008; 10:247.

18. Van Landuyt $K L$, Peumans $M$, Fieuws $S$, De Munck J, Cardoso MV, Ermis RB, Lambrechts P, Van Meerbeek B. A randomized controlled clinical trial of a HEMA-free all-in-one adhesive in non-carious cervical lesions at 1 year. J Dent 2008;36:847-55.

19. Hickel R, Roulet JF, Bayne S, Heintze D, Mjör IA, Peters M, Rousson V, Randall R, Schmalz G, Tyas $M$, Vanherle G. Recommendations for Conducting 
Controlled Clinical Studies of Dental Restorative Materials Science Committee Project 2/98 - FDI World Dental Federation Study Design (Part I) and Criteria for Evaluation (Part II) of Direct and Indirect Restorations Including Onlays and Partial Crowns. J Adhes Dent 2007;9:121-47.

20. Peumans M, De Munck J, Van Landuyt $\mathrm{KL}$, Kanumilli $\mathrm{P}$, Yoshida Y, Inoue S, Lambrechts $P$, Van Meerbeek B. Restoring cervical lesions with flexible composites. Dent Mater 2007;23:749-54.

21. Gresnigt MM, Kalk W, Ozcan M. Randomized controlled split-mouth clinical trial of direct laminate veneers with two micro-hybrid resin composites. J Dent 2012;40:766-75.

22. Kubo S, Kawasaki K, Yokota H, Hayashi Y. Fiveyear clinical evaluation of two adhesive systems in non-carious cervical lesions. J Dent 2006;34:97105.

23. Council on dental materials, instruments and equipment. Revised American Dental Association acceptance program guidelines for dentin and enamel adhesive materials, January 1994.

24. Van Dijken JWV. Clinical evaluation of three adhesive systems in class $\mathrm{V}$ non-carious lesions. Dent Mater 2000;16:285-91.

25. van Dijken JW, Sunnegårdh-Grönberg K, Lindberg A. Clinical long-term retention of etch-and-rinse and self-etch adhesive systems in non-carious cervical lesions. A 13 years evaluation. Dent Mater 2007;23:1101-7.

26. Ritter AV, Heymann HO, Swift EJ Jr, Sturdevant JR, Wilder AD Jr. Clinical evaluation of an all-in-one adhesive in non-carious cervical lesions with different degrees of dentin sclerosis. Oper Dent 2008;33:370-8.

27. Türkün LS. The clinical performance of one- and two-step self-etching adhesive systems at one year. J Am Dent Assoc 2005;136:656-64.

28. Türkün LS, Celik EU. Noncarious class V lesions restored with a polyacid modified resin composite and a nanocomposite: a two-year clinical trial. J Adhes Dent 2008;10:399-405.

29. Tuncer D, Yazici AR, Özgünaltay G, Dayangac B. Clinical evaluation of different adhesives used in the restoration of non-carious cervical lesions: 24month results. Aust Dent J 2013;58:94-100.

30. Aw TC, Lepe X, Johnson GH, Mancl L. One-year clinical evaluation of an ethanol-based and a solvent-free dentin adhesive. Am J Dent 2004;17:451-6.

31. van Dijken JW. Durability of three simplified adhesive systems in Class $\mathrm{V}$ non-carious cervical dentin lesions. Am J Dent 2004;17:27-32.

32. Bittencourt DD, Ezecelevski IG, Reis A, Van Dijken JW, Loguercio AD. An 18-months' evaluation of self-etch and etch \& rinse adhesive in non-carious cervical lesions. Acta Odontol Scand 2005;63:1738.

33. Aw TC, Lepe $X$, Johnson GH, Mancl LA. A threeyear clinical evaluation of two-bottle versus onebottle dentin adhesives. J Am Dent Assoc 2005;136:311-22.

34. Brackett WW, Brackett MG, Dib A, Franco G, Estudillo H. Eighteen-month clinical performance of a self-etching primer in unprepared class V resin restorations. Oper Dent 2005;30:4249.

35. Perdigão J, Carmo AR, Anauate-Netto C, Amore R, Lewgoy HR, Cordeiro HJ, Dutra-Corrêa M, Castilhos $\mathrm{N}$. Clinical performance of a self-etching adhesive at 18 months. Am J Dent 2005;18:135-40.

36. Meerbeek BV, Kanumilli P, De Munck J, Van Landuyt $K$, Lambrechts $P$, Peumans $M$. A randomized controlled study evaluating the effectiveness of a two-step self-etch adhesive with and without selective phosphoric-acid etching of enamel. Dent Mater 2005;21:375-83.

37. Abdalla AI, García-Godoy F. Clinical evaluation of self-etch adhesives in Class $\mathrm{V}$ non-carious lesions. Am J Dent 2006;19:289-92.

38. Saboia Vde P, Almeida PC, Rittet AV, Swift EJ Jr, Pimenta LA. 2-year Clinical evaluation of sodium hypochlorite treatment in the restoration of noncarious cervical lesions: a pilot study. Oper Dent 2006;31:530-5.

39. Burrow MF, Tyas MJ. Clinical evaluation of three adhesive systems for the restoration of noncarious cervical lesions. Oper Dent 2007;32:11-5.

40. Matis BA, Cochran MJ, Carlson TJ, Guba C, Eckert GJ. A three-year clinical evaluation of two dentin bonding agents. J Am Dent Assoc 2004;135:451-7.

41. van Dijken JW, Pallesen U. Long-term dentin retention of etch-and-rinse and self-etch adhesives and a resin-modified glass ionomer cement in noncarious cervical lesions. Dent Mater 2008;24:91522.

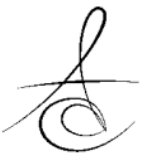


42. Burrow MF, Tyas MJ. A clinical trial comparing two all-in-one adhesive systems used to restore noncarious cervical lesions: results at one year. Aust Dent J 2008;53:235-8.

43. Reis A, Loguercio AD. A 36-month clinical evaluation of ethanol/water and acetone-based 'etch-and-rinse' adhesives in non-carious cervical lesions. Oper Dent 2009;34:384-91.

44. Ritter AV, Swift EJ Jr, Heymann HO, Sturdevant JR, Wilder AD Jr. An eight-year clinical evaluation of filled and unfilled one-bottle dental adhesives. J Am Dent Assoc 2009;140:28-37.

45. Kubo S, Yokota H, Yokota H, Hayashi Y. Twoyear clinical evaluation of one-step self-etch systems in non-carious cervical lesions. J Dent 2009;37:149-55.

46. Kim SY, Lee KW, Seong SR, Lee MA, Lee IB, Son $\mathrm{HH}$, Kim HY, Oh MH, Cho BH. Two-year clinical effectiveness of adhesives and retention form on resin composite restorations of non-carious cervical lesions. Oper Dent 2009;34:507-15.

47. Loguercio AD, Mânica $\quad D$, Ferneda $F$, ZanderGrande C, Amaral R, Stanislawczuk R, de Carvalho RM, Manso A, Reis A. A randomized clinical evaluation of a one- and two-step self-etch adhesive over 24 months. Oper Dent 2010;35:26572.

48. Peumans $M$, De Munck J, Van Landuyt $\mathrm{KL}$, Poitevin A, Lambrechts P, Van Meerbeek B. Eight-year clinical evaluation of a 2-step self-etch adhesive with and without selective enamel etching. Dent Mater 2010;26:1176-84.

49. Santiago SL, Passos VF, Vieira AH, Navarro MF, Lauris JR, Franco EB. Two-year clinical evaluation of resinous restorative systems in non-carious cervical lesions. Braz Dent J 2010;21:229-34.

50. Van Dijken JW. A prospective 8-year evaluation of a mild two-step self-etching adhesive and a heavily filled two-step 'etch-and-rinse' system in noncarious cervical lesions. Dent Mater 2010;26:9406.

51. Burrow MF. Clinical evaluation of non-carious cervical lesion restorations using a HEMA-free adhesive: three-year results. Aust Dent J 2011;56:401-5.

52. Van Landuyt KL, Peumans M, De Munck J, Cardoso MV, Ermis B, Van MeerbeekB. Three-year clinical performance of a HEMA-free one-step self-etch adhesive in non-carious cervical lesions. Eur J Oral Sci 2011;119:511-6.

53. Fron $\mathrm{H}$, Vergnes JN, Moussally $\mathrm{C}$, Cazier $\mathrm{S}$, Simon AL, Chieze JB, Savard G, Tirlet G, Attal JP. Effectiveness of a new one-step self-etch adhesive in the restoration of non-carious cervical lesions: 2-year results of a randomized controlled practicebased study. Dent Mater 2011;27:304-12.

54. Burrow MF, Tyas MJ. Clinical investigation of GBond resin-based adhesive to non-carious cervical lesions over five years. Aust Dent J 2012;57:45863.

55. Van Dijken JWV. Pallesen U. A 7-year randomized prospective study of a one-step self-etching adhesive in non-carious cervical lesions. The effect of curing modes and restorative material. J Dent 2012;40:1060-7.

56. Burrow MF, Tyas MJ. Comparison of two all-in-one adhesives bonded to non-carious cervical lesions-results at 3 years. Clin Oral Investig 2012;16:108994.

57. Perdigão J, Dutra-Corrêa M, Saraceni SH, Ciaramicoli MT, Kiyan VH. Randomized clinical trial of two resin-modified glass ionomer materials: 1year results. Oper Dent 2012;37:591-601.

58. Söderholm KJ, Ottenga M, Nimmo S. Four-year clinical evaluation of two self-etching dentin adhesives of different $\mathrm{pH}$ values used to restore non-retentive cervical lesions. Am J Dent 2013; 26:28-32.

59. Dutra-Correa $\mathrm{M}$, Saraceni $\mathrm{CH}$, Ciaramicoli MT, Kiyan VH, Queiroz CS. Effect of chlorhexidine on the 18-month clinical performance of two adhesives. J Adhes Dent 2013;15:287-92.

60. Moosavi H, Kimyai S, Forghani M, Khodadadi R. The clinical effectiveness of various adhesive systems: an 18-month evaluation. Oper Dent 2013; 38:134-41.

61. Da Costa TR, Loguercio AD, Reis A. Effect of enamel bevel on the clinical performance of resin composite restorations placed in non-carious cervical lesions. J Esthet Restor Dent 2013;25:34656.

62. Can Say E, Ozel E, Yurdagüven H, Soyman $M$. Three-year clinical evaluation of a two-step selfetch adhesive with or without selective enamel etching in non-carious cervical sclerotic lesions. 
Clin Oral Investig 2014;18:1427-33.

63. Zander-Grande C, Amaral RC, Loguercio AD, Barroso LP, Reis A. Clinical performance of onestep self-etch adhesives applied actively in cervical lesions: 24-month clinical trial. Oper Dent 2014; 39:228-38.

64. Preussker $S$, Pöschmann $M$, Kensche A, Natusch I, Koch R, Klimm W, Hannig C. Three-year prospective clinical performance of a one-step selfetch adhesive and a nanofiller hybrid resin composite in Class $\mathrm{V}$ lesions. Am J Dent 2014;27:73-8.

65. Torres RGC, Barcellos DC, Batista GR, Pucci CR, Antunes MJ, de La Cruz DB, Borges AB. Five-year clinical performance of the dentine deproteinization technique in non-carious cervical lesions. J Dent. 2014;42:816-23.

66. Kurokawa H, Miyazaki M, Takamizawa T, Rikuta A, Tsubota K, Uekusa S. One-year clinical evaluation of five single-step self-etch adhesive systems in non-carious cervical lesions. Dent Mater J 2007; 26: 14-20.

67. Hayashi M, Tsuchitani Y, Kawamura Y, Miura M, Takeshige $F$, Ebisu S. Eight year clinical evaluation of fired ceramic inlays. Oper Dent 2000;25:473-81.

68. Mjor IA. Clinical diagnosis of recurrent caries. J Am Dent Assoc 2005;136:1426-33.

69. Hayashi M, Wilson NH. Failure risk of posterior composites with post-operative sensitivity. Oper Dent 2003;28:681-8.

70. Heintze S. Systematic Reviews: I. The correlation between laboratory tests on marginal quality and bond strength. II. The correlation between marginal quality and clinical outcome. J Adhes Dent 2007;9:77-106.

71. Brunthaler A, König F, Lucas T, Sperr W, Schedle A. Longevity of direct resin composite restoration in posterior teeth. Clin Oral Investig 2003;7:63-70.

72. Opdam NJ, Bronkhorst EM, Roeters JM, Loomans BA. A retrospective clinical study on longevity of posterior composite and amalgam restorations. Dent Mater 2007;23:2-8.

73. Ülker E, Tuncdemir T, Erkan Aİ, Malkoc MA, Cobanoglu N. İki self-etch bonding sistemin biyouyumluluklarının ve bağlanma dayanımlarının değerlendirilmesi. Atatürk Üni Diş Hek Fak Derg 2014;24:44-9.
74. Loguercio AD, Lorini E, Weiss RV, Tori AP, Picinatto CC, Ribeiro NR, Reis A. A 12-month clinical evaluation of composite resins in class III restorations. J Adhes Dent 2007;9:57-64.

75. Yuan Y, Shimada Y, Ichinose S, Tagami J. Effect of dentin depth on hybridization quality using different bonding tactics in vivo. J Dent 2007;35:664-72.

76. Mine A, De Munck J, Cardoso MV, Van Landuyt KL, Poitevin A, Kuboki T, Yoshida $Y$, Suzuki K, Lambrechts $P$, Van Meerbeek B. Bonding effectiveness of two contemporary self-etch adhesives to enamel and dentin. J Dent 2009;37:872-3.

\section{Yazışma Adresi}

Neslihan Tekçe

Kocaeli Üniversitesi

Diş Hekimliği Fakültesi,

Restoratif Diş Tedavisi AD

Yuvacık yerleşkesi, KOCAELI

Tel: 02623442222

E-posta: neslihan_arslann@hotmail.com 